\title{
INVESTIGATION OF THE RELATIONSHIP BETWEEN IONOSPHERIC TEC ANOMALY VARIATIONS AND FAULT TYPES BEFORE THE EARTHQUAKES
}

\author{
M. Ulukavak ${ }^{a *}$, M. Yalçınkaya ${ }^{\mathrm{b}}$ \\ ${ }^{\text {a }}$ Harran University, Engineering Faculty, Dept. of Geomatics Engineering, 63300 Sanliurfa, Turkey - mulukavak@ gmail.com \\ b Karadeniz Technical Uni., Engineering Faculty, Dept. of Geomatics Engineering, 61080 Trabzon, Turkey - mualla@ktu.edu.tr
}

KEY WORDS: Earthquake, TEC, GPS, Space Weather Condition, Fault Type

\begin{abstract}
:
Earthquakes are natural phenomena that shake the earth and cause many damage. Since the time of arrival of the earthquakes cannot be determined directly, some signs before the earthquake should be examined and interpreted by examining the environmental changes. One of the methods used for this is monitoring the ionospheric total electron content (TEC) changes in total electron content unit (TECU). GPS satellites have begun to be used as a means of monitoring ionospheric TEC anomalies before earthquakes since they began to be used as sensors around the world. In this study, three fault type (normal, thrust and strike-slip faulting) of 28 earthquakes with a magnitude greater than $7(\mathrm{Mw})$ and the percentage changes of TEC anomalies before the earthquakes were investigated. The ionospheric TEC anomalies before the earthquake were calculated according to the 15-day running median statistical analysis method. Different solar and geomagnetic indices have been investigated to determine the active space weather conditions and quiet days before and after the earthquake. The TEC anomalies were determined during the quiet days before the earthquake by comparing the ionospheric anomalies that occurred before the earthquake after the determination of quiet days with the indices of the space weather conditions. The results show that there is a relationship between fault type and the earthquake precursor percentage changes and were determined as $47.6 \%$ TECU for regions where normal faulting, 50.4\% TECU for regions where thrust faulting, and 44.2\% TECU for regions where strike-slip faulting occurred, respectively.
\end{abstract}

\section{INTRODUCTION}

Data obtained from dual-frequency global navigation satellite system (GNSS) receivers have recently been used both for ionospheric studies and for accurate positioning. Dual-frequency global positioning system (GPS) receivers are used to derive total electron content (TEC), which provide users with additional information on the upper atmosphere. The great Alaska earthquake in 1964 was the first earthquake whose seismicionospheric anomalies were observed (Davies and Baker 1965). Earthquake precursors have been a research interest for a significant number of scientists (Silina et al. 2001, Liperovskaya et al. 2000, Zhou et al. 2009, Dogan et al. 2011, Jyh-Woei 2011, Ulukavak 2016). Some studies have focused on the relationship between seismic events and unforeseen variations in ionospheric activity (Parrot et al. 1993, Depueva 2012). Both satellite- and ground-based instruments have been used to examine seismoionospheric effects (Astafyeva and Heki 2011, Aggarwal 2015). Several hypotheses on the seismic and electromagnetic mechanism of geochemical and geophysical processes have also been explained by Pulinets and Boyarchuk (2004). Seismioionospheric anomalies generally occur in the $\mathrm{D}, \mathrm{E}$, and $\mathrm{F}$ layers of the ionosphere and may appear one day to ten days before the earthquake (Hayakawa and Molchanov 2002, Pulinets and Boyarchuk 2004, Priyadarshi et al. 2011).

A fault is called the zone between two tectonic plates or blocks. Faults allow the blocks to move relative to each other. The movement of the plates can occur quickly or slowly. During an earthquake, the rock on one side of the fault suddenly slips with respect to the other. The fault surface can be horizontal or vertical or some arbitrary angle in between (URL-2, 2014). There are essentially three types of faults. These are normal fault, thrust fault and strike slip fault. Normal faults are inclined fractures where the blocks have mostly shifted vertically. If the rock mass above an inclined fault moves down, the fault is termed normal, whereas if the rock above the fault moves up, the fault is termed a reverse fault. A thrust fault is a reverse fault with a dip of $45^{\circ}$ or less, a very low angle. When the dip angle is shallow, a reverse fault is often described as a thrust fault. Strike-slip faults are vertical (or nearly vertical) fractures where the blocks have mostly moved horizontally. If the block opposite an observer looking across the fault moves to the right, the slip style is termed right-lateral; if the block moves to the left, the motion is termed left-lateral (URL-2, 2014). Because of these characteristics, the fault types apply different specific forces to the fault surfaces (Frohlich, 2006). Considering the forces applied on the granite block experiment in Freund 2005, we have examined the variations of ionospheric TEC anomalies in different types of faults. The results show that there is a relationship between fault type and the earthquake precursor percentage changes (on ionospheric TEC anomalies).

\section{ESTIMATION OF GPS-TEC VARIATIONS}

Changes in pre-earthquake ionospheric TEC can be determined by GNSS data. The geometry-free linear combination of the code $(P)$ or carrier-phase $(\Phi)$ measurements can be used to estimate the ionospheric TEC (Schmidt et al. 2008). The geometry free linear combination for pseudo-range measurements $P_{4}$ can be calculated by subtracting the measurements of the $P_{2}$ code from the $P_{l}$ code (Schaer 1999). DCBs should be determined to obtain unbiased STEC. However, a standard procedure on how to include these DCBs into TEC computation has yet to be determined (Warnant 1997, Makalea et al. 2001). DCBs are eliminated in STEC calculation as follows:

$$
\operatorname{STEC}_{u}^{m}(n)=\frac{1}{A}\left(\frac{f_{1}^{2} f_{2}^{2}}{f_{2}^{2}-f_{1}^{2}}\right)\left[P_{4, u}^{m}(n)-D C B^{m}+D C B_{u}\right](1)
$$


where $f_{1}$ and $f_{2}$ are the carrier frequencies of L1 and L2 signals of GPS satellites. $A\left(40.3 \mathrm{~m}^{3} / \mathrm{s}^{2}\right)$ and $S T E C_{u}^{m}$ indicate the Slant Total Electron Content (STEC) in units of TECU (1 TECU $=10^{16}$ electrons $/ \mathrm{m}^{2}$ ) on the slant signal path from the receiver $u$ and satellite $m . D C B^{m}$ and $D C B_{u}$ are the differential code biases (DCBs) defined for pseudo-range measurements, index $\mathrm{n}$ denotes the time sample ranges from 1 to $N$ (total number of time samples in a record)(Komjathy 1997, Dach et al. 2007, Jin et al. 2012). VTEC can be obtained using a thin shell approximation (Klobuchar 1986) of the single layer ionosphere model for which the relation between STEC and VTEC is given as follows:

$$
M\left(z_{m}(n)\right)=\frac{\operatorname{STEC}_{u}^{m}(n)}{\operatorname{VTEC}_{u}^{m}(n)}
$$

where the mapping function $z m(n)$ is defined as the satellite zenith angle at the receiver position. The mapping function $M(z)$ is defined as follows:

$$
M(z)=\frac{1}{\cos z^{\prime}}=\frac{1}{\sqrt{1-\sin ^{2} z^{\prime}}}, \sin z^{\prime}=\frac{R}{R+H} \sin (\alpha z)
$$

where, $z^{\prime}$ is the zenith angle at the ionospheric pierce point (IPP) where the line-of-sight between the satellite and ground receiver intersects the thin shell. $R$ is the earth radius $(6,378.137 \mathrm{~km})$, $\alpha=0.9886$ is a scaling factor from the modified single layer mapping function (Schaer 1999) and $H$ is the ionospheric shell height $350 \mathrm{~km}$ (Mannucci et al. 1993). The calibrated STEC variations are obtained by removing the estimated DCBs from each satellite arc in equation (1). The VTEC values are determined using equation (2) for each continuous arc. In this study, the hourly VTEC values are estimated with the calibrated VTEC values at IPP over each GNSS station by fitting the approximation of second-order polynomial surfaces to IPP points for a 24-hour run (Durmaz and Karslioglu 2014).

$$
\begin{aligned}
& \operatorname{VTEC}\left(\varphi_{I P P}, s_{I P P}\right)=a_{0}+a_{1} \varphi_{I P P}+a_{2} s_{I P P}+\ldots \\
& +a_{3} \varphi_{I P P}{ }^{2}+a_{4} \varphi_{I P P} s_{I P P}+a_{5} s_{I P P}{ }^{2}
\end{aligned}
$$

where $\varphi_{I P P}$ and $S_{I P P}$ are the spherical coordinates of the IPP in the sun-fixed reference frame; $a_{0}, a_{1}, a_{2}, a_{3}, a_{4}$ and $a_{5}$ are the polynomial surface coefficients. The topside hourly VTEC values at each station are calculated by substituting the sun-fixed spherical coordinates of each station alongside the estimated polynomial surface coefficients in equation (4). Insufficient data will reveal problems in estimating the hourly VTEC value. However, the missing VTEC values above the stations should also be completed by interpolating the grid TEC data obtained from IGS IONEX files (Schaer et al. 1998).

\section{ANALYSIS OF VTEC ANOMALIES}

Investigation on the pre-earthquake ionospheric VTEC anomalies can be performed by using 15-day moving median (MM) methods that employ the quartile based statistical analysis method (Liu et al. 2009). The MM values of GPS-TEC were calculated in advance by using the quartile-based statistical analysis method. The lower quartile (LQ) and upper quartile (UQ) were also calculated. Assuming that the GPS-TEC values are in the normal distribution with mean $(\mathrm{m})$ and standard deviation $(\sigma)$, the expected values of MM and LQ or UQ are $m$ and $1.34 \sigma$, respectively (Klotz and Johnson 1983). The lower bound (LB) and upper bound (UB) are calculated as $\mathrm{LB}=\mathrm{MM}$ 1.5(MM-LQ) and $\mathrm{UB}=\mathrm{MM}+1.5(\mathrm{UQ}-\mathrm{MM})$, respectively. Anomalous variations can be detected in observed GPS-TEC greater than UB or lesser than the associated LB (Liu et al. 2009). For example, the VTEC values for the first 15 days were used to generate MM, UB and LB for the 16th day. Similarly, 15 days of VTEC data between the 2nd and 16th day are used to generate bounds for the 17th day. If more than one- third of the data (e.g., eight hours are anomalous in a day) are greater or lesser than these UBs and LBs in a day, this day is taken as anomalous (Liu et al. 2009).

\section{PHYSICAL MECHANISM OF EARTHQUAKE AND IONOPHERIC ANOMALIES}

Since the changes in the preparatory stage before the earthquakes cannot be directly determined, it is more appropriate to reveal these effects indirectly by looking at the environmental changes. On the other hand, these effects may have been affected by geological or atmospheric conditions, but seismic activity and the effects that trigger these changes have not yet been fully explained (Guo and Wang, 2008; Pulinets et al. 2006; Tronin et al. 2002, 2004; Fidani, 2010; Ikeya, 2004). In times of great earthquakes, the earth's crust sometimes spreads strong, often weak, and sometimes short-lived. These signals include local magnetic field changes, electromagnetic emissions in a wide frequency range, and atmospheric and ionospheric events. When the rocks on the earth are pressed, the peroxy bonds are broken and the electrically charged carriers are released to form positive holes. Positive holes are very mobile and can easily carry free volumes from trapped volumes. In a system similar to the battery system, when the battery terminals are combined, the electric current generated by the positive current passage reveals magnetic field variations and low frequency electromagnetic propagation. When positive holes reach the earth, ionization occurs at the ground-air interface. Rising ionized air can be seen as a possible cause of irregularities in the ionosphere (Freund, 2011). Today, there are studies that do not reveal the relationship between electron density change and seismic activity (Pulinets, 1998; Namgaladze vd., 2009). The first hypothesis to be made in this area is the electric current, i.e. piezoelectric effect that comes from the trapped rocks. In a laboratory experiment, pressure was applied to the upper surface of the granite block and ionization occurred in the air environment on the side surfaces of the granite block (Freund, 2005). At the pressure applied end of the rock block, electrons $\left(\mathrm{e}^{-}\right)$and the charge carrier holes $\left(\mathrm{h}^{\circ}\right)$, which flow through the trapped rock volume to the non-trapping volume, form a potential difference. This condition acts as an open circuit electrochemical battery. The jammed volume is negative and the jammed volume is loaded with positive charges. The load carrier $\mathrm{h}^{\bullet}$ allows the positive holes to be held on the surface. Strong electron flow towards the uncompressed sides of the rocks compacted in the laboratory environment was observed in the granite block. The spatial expansion of this experiment will form the proven and confined rocks - Earth surface changesatmosphere-ionosphere system that will cause ionization in the rocks with the stress accumulated in the fault fractures before the strong earthquakes and to spread the ionized air to the ionosphere layer in the rock fractures and increase the electron density in the ionosphere (St-Laurent et al., 2006; Freund et al., 2006; Kuo et al., 2011). By using these hypothesis we have classified earthquakes by fault types with ionospheric TEC anomalies.

\section{RESULTS AND CONCLUSIONS}

In this study, GPS-TEC data were used to investigate ionospheric abnormal behaviours prior to 28 earthquakes (Figure 1). 


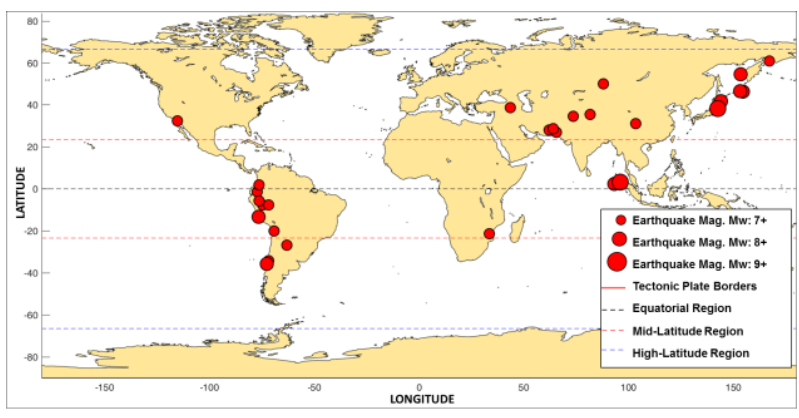

Figure 1. Selected earthquakes and locations around the world.

All maps, graphics, calculations and some statistical procedures were performed by MATLAB ${ }^{\circledR}$ scripts. For these earthquakes, the radius of the earthquake preparation zones (EPZ) were estimated using the Dobrovolsky formula: $\rho=10^{0.43 * M}$, where $\rho$ is the radius of the EPZ $(\mathrm{km})$ and $\mathrm{M}$ is the magnitude of the earthquake on the moment magnitude scale (Dobrovolsky et al. 1979). The radius of the EPZs for the earthquakes were calculated. IGS stations in the vicinity of the earthquake zone were obtained. According to Oyama et al. 2008, the disturbed region extends across a wide range of latitudes and longitudes such as $60^{\circ}$ in the East-West direction and $40^{\circ}$ in the NorthSouth direction for large earthquakes of magnitude $(M>6)$. Hence, in this study we also selected at least one IGS station outside of the EPZs. The earthquake (EQ) is a localized phenomenon and space weather conditions are a global phenomenon therefore we have selected one IGS away from the earthquake epicentre. The IGS RINEX files, SP3 (precise satellite orbits) files, and IGS IONEX (Ionospheric TEC maps and Satellite DCBs) files were obtained from the GNSS data and products archive of Crustal Dynamics Data and Information System to investigate the anomalous variations on ionospheric TEC during the earthquake. These data are available from the website ftp://cddis.gsfc.nasa.gov.

Since, 28 earthquake data could not be added in this paper, only data for the 2010 Baja California earthquake (Mw: 7.2, 32.128 N, $115.303^{\circ} \mathrm{W}$, April 4, 2010, 22:40:41 UTC) was added. Hourly GPS-TEC data 30 days before and 15 days after the earthquake were processed by following the methodology explained in Section 2. In order to check the reliability of DCB estimations, the estimated DCBs of stations were compared with the estimates in the IGS IONEX files (Figure 2).

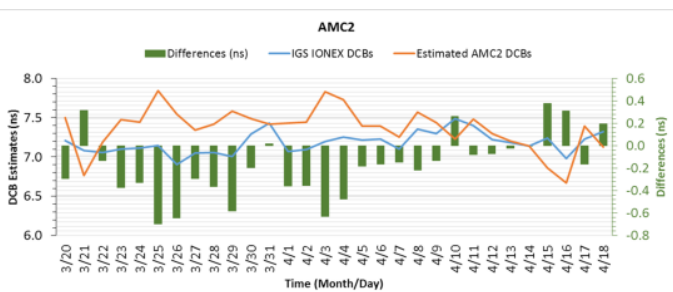$$
\text { AMC }
$$

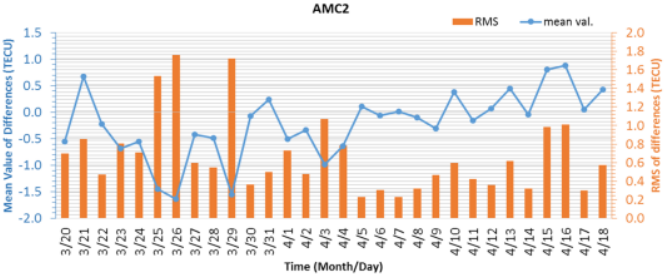

Figure 2. Comparison between the daily receiver DCB estimates and GPS-TEC values of the AMC2 station between March 20 and April 18, 2010.

A comparison between the DCBs estimated from the AMC2 station and the DCBs from the IGS IONEX files revealed a difference of less than 1 ns. The calculated RMS (Root Mean Square) of differences of the estimated AMC2 IGS receiver DCBs and value of the IGS IONEX file is $\pm 0.29 \mathrm{~ns}$. The results indicate that the estimated AMC2 site receiver DCBs may be considered reliable. The accuracy of IGS IONEX TEC values were defined in the range of 2-8 TECU (https://igscb.jpl.nasa.gov/components/prods.html). The results in figure 2 show, that the calculated mean and RMS of GPS-TEC values are within the acceptable range and hence can be considered reliable.

An example of the LBs, UBs, and MM values were calculated using daily variations in the one-hour resolution of GPS-TEC data calculated from selected five IGS sites close to the earthquake epicentre and one IGS station away from the epicentre (Figure 3).

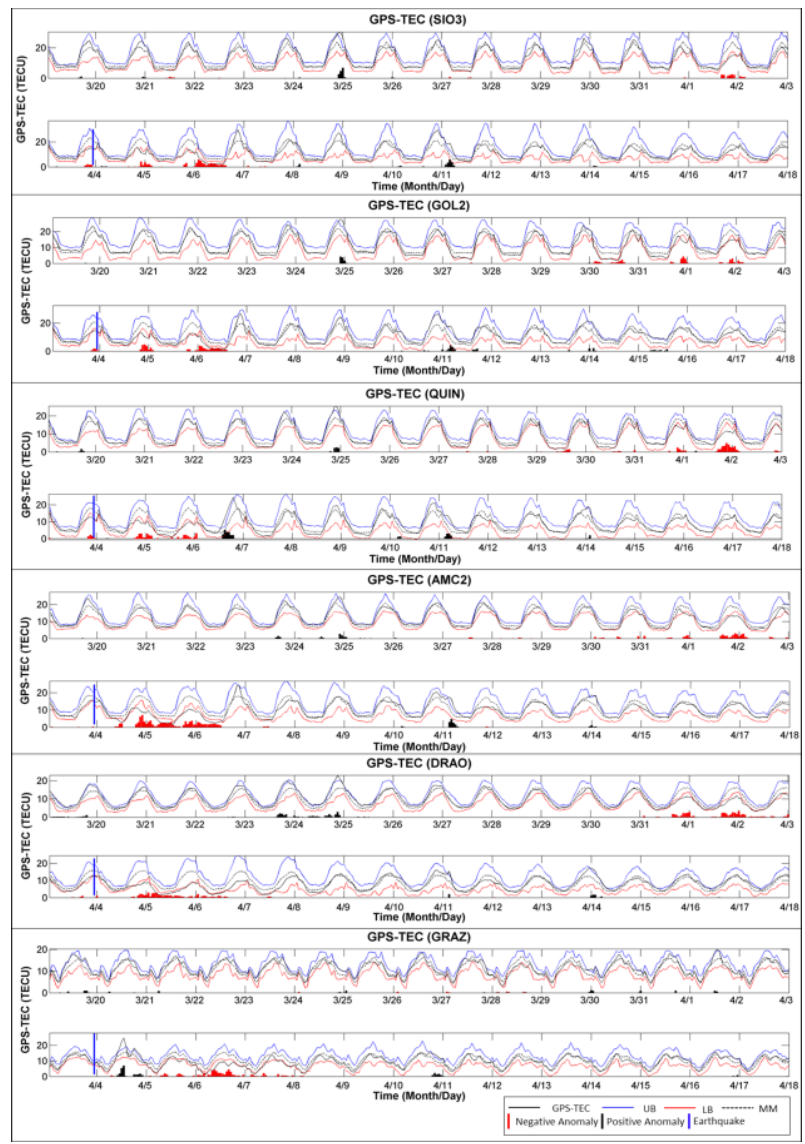

Figure 3. GPS-TEC time series data from selected IGS stations during the period from March 20 to April 18, 2010.

In Figure 3, blue vertical line show the earthquake occurrence moment; black line show estimated GPS-TEC variations; blue line show upper bound (UB); red line show lower bound (LB); dashed black line show median values (MM); black coloured bars show positive anomalies; red coloured bars show negative anomalies before and after the earthquake. 
TEC data were analysed using the 15-day MM method analysed using the methodology explained in Section 3 (Figure 4). The LBs, UBs, and MM values were calculated using daily variations in the one-hour resolution of GPS-TEC data calculated from selected IGS sites close to the earthquake epicentre and one IGS station away from the epicentre.

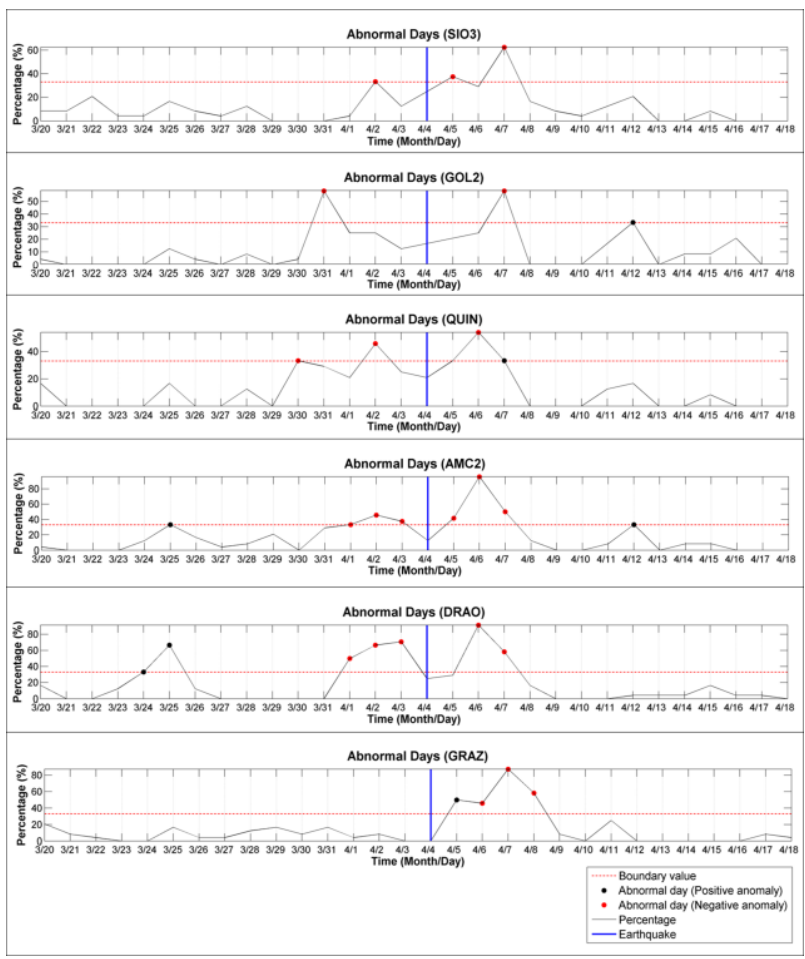

Figure 4 . The percentage of the anomalous days during the period from March 20 to April 18, 2010.

In Figure 4, blue vertical line show the earthquake occurrence moment; black line show percentages; horizontal dashed red line show boundary value; black dots show abnormal days with positive anomaly and red dots show abnormal days with negative anomaly.

The ionospheric parameters are mainly affected by solar geophysical conditions and geomagnetic storms, especially in the Equatorial and Polar Regions. When discussing the relationship between ionospheric anomaly and earthquake, the solar terrestrial environment must be considered to exclude anomalies that may have been caused by solar or geomagnetic activities (Pulinets et al. 2003, Ulukavak and Yalcinkaya 2014, 2016). Geomagnetic and solar indices (i.e., Dst, Kp, F10.7 and EUV) are obtained for space weather conditions. We accessed the geomagnetic storm indices (Dst) from the archive of the Data Analysis Center for Geomagnetism and Space Magnetism Graduate School of Science of Kyoto University via the link http://wdc.kugi.kyoto-u.ac.jp/dstae/index.html. The Kp indices data from the National Oceanic and Atmospheric Administration are archived

in ftp://ftp.ngdc.noaa.gov/STP/GEOMAGNETIC_DATA/INDICE S/KP_AP/. The solar radio flux $(\mathrm{F} 10.7 \mathrm{~cm})$ data from the Canadian Space Weather Forecast Center in Ottawa from http://www.spaceweather.gc.ca/solarflux/sx-en.php and EUV Flux were obtained from the University of Southern California Space Sciences Center achieve from http://www.usc.edu/dept/space_science/semdatafolder/semdown load.htm.In this study, we investigated the geomagnetic and solar indices (Dst, F10.7, EUV and $\mathrm{Kp}$ ) to distinguish seismic anomalies from other anomalies related to space weather conditions The earth's ionosphere is effected by various facts, from space to ground due to the variation in geomagnetic activity, solar activity, meteorological events, and human-induced effects (Aggarwal 2015). The ionosphere also presents normal day-today, seasonal and diurnal variations making it difficult to identify possible pre-earthquake ionospheric anomalies as it changes the ionospheric parameters, such as GPS-TEC, on a regional scale (Afraimovich and Astafyeva 2008). All space weather condition indices values are evaluated together and identified as quiet before the earthquake (Figure 5).

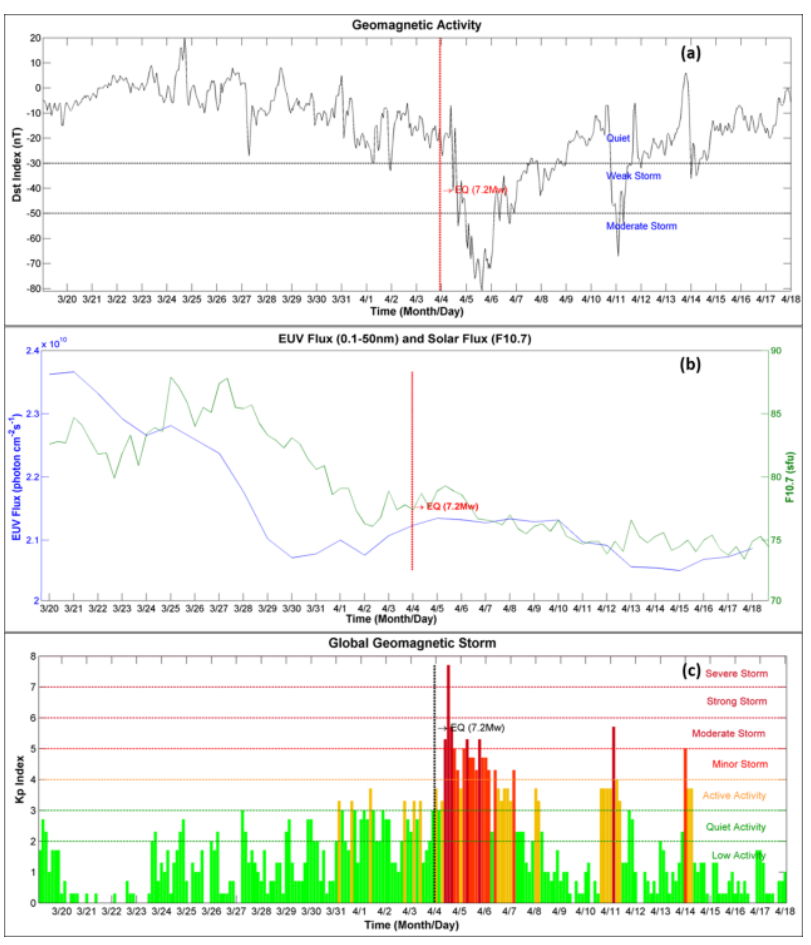

Figure 5. Dst, EUV, F10.7, and Kp indices during the period from March 20 to April 18, 2010.

In this work the effect of GPS-TEC day-to-day changes before strong earthquake which were occurred in different fault types are analysed. The relationships of these anomalies to the fault type of the earthquakes have been investigated. The results show that there is a relationship between fault type and the earthquake precursor percentage changes. The percentages of ionospheric TEC anomalies were determined as $47.6 \%$ TECU for regions where normal faulting, 50.4\% TECU for regions where thrust faulting, and $44.2 \%$ TECU for regions where strike-slip faulting occurred, respectively. When the geo-tectonic structure of the regions where the earthquakes occur and the pre-earthquake ionospheric TEC anomalies are evaluated together, It was found that the pre-earthquake ionospheric TEC anomaly percentages calculated for the earthquakes in the thrust faulting regions where the earthquakes occurred were higher than those of the normal and strike-slip faulting regions.

As a first reason, it can be said that the electron emissions are more easily spread to the atmosphere due to the fact that the fault surfaces resulting from normal and thrust faulting become more open than the fault surfaces that appear in strike-slip faults (Figure 6), (Frohlich, 2006; URL-1, 2 and 3). 


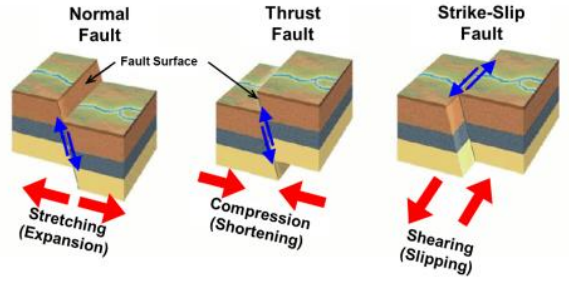

Figure 6. Opening fault surfaces according to fault types

The second cause of the resulting anomaly difference is the increase in the electron emission of the pressure generated by normal and inverse faulting and the application of a force in the direction perpendicular to the fault or in the vicinity of the fault. It can be argued that electron emission, which occurs as a result of applying parallel force to the fault surface in strike-slip faults, occurs at a lower rate (Figure 6), (Freund, 2005).

This increase in the force applied to the fault surface may be due to the application of positive or negative ion formations that will occur in proportion to the magnitude of the earthquake energy to be produced and to the application of more pressure (energy accumulation) to the fault surface of the forces that will increase electron emissions.

\section{ACKNOWLEDGEMENTS}

The authors would like to thank, the CDDIS (Crustal Dynamics Data and Information System) data and products archive, for providing the RINEX, SP3 and IONEX files, NASA Goddard Space Flight Center's Space Physics Data Facility, Data Analysis Center for Geomagnetism and Space Magnetism Graduate School of Science of Kyoto University and The solar radio flux $(\mathrm{F} 10.7 \mathrm{~cm})$ data from the Canadian Space Weather Forecast Center in Ottawa for providing the space weather condition indices, The University of Southern California Space Sciences Center CELIAS/ SEM experiment on the Solar Heliospheric Observatory (SOHO) spacecraft mission for providing the EUV flux data, United States Geological Survey Agency for providing earthquake data. This research is supported by TUBITAK CAYDAG grant no. 116Y109.

\section{REFERENCES}

Aggarwal, M., 2015. Anomalous changes in ionospheric TEC during an earthquake event of 13-14 April 2010 in the Chinese sector. Advances in Space Research. 56, pp. 1400-1412.

Afraimovich, E. L., Astafyeva, E. I., 2008. TEC anomalies local TEC changes prior to earthquakes or TEC response to solar and geomagnetic activity changes? Earth Planets Space. 60, pp. 961966.

Astafyeva, E., Heki, K., 2011. Vertical TEC over seismically active region during low solar activity. J. Atmos. Sol. Terr. Phys. 73(13), pp. 1643-1652.

Dach, R., Hugentobler, U., Fridez, P., Meindl, M., 2007. Manual of Bernese GPS Software Version5.0, Astronomical Institute, University of Bern. Bern.

Davies, K., Baker, D. M., 1965. Ionospheric Effects Observed Around Time of Alaskan Earthquake of March 28 1964. J. Geophy. Res. 70, pp. 2251-2253.
Depueva, A., 2012. Peculiarities of low-latitude and equatorial ionosphere prior to strong earthquakes. Geomatics, Natural Hazards and Risk. 3(3), pp. 207-224.

Dobrovolsky, I. P., Zubkov, S. I., Miachkin, V.I., 1979. Estimation of the Size of Earthquake Preparation Zones, Pure. Appl. Geophys. 117, pp. 1025-1044.

Dogan, U., Ergintav, S., Skone, S., Arslan, N., Oz, D., 2011. Monitoring of the ionosphere TEC variations during the 17th August 1999 Izmit earthquake using GPS data. Earth Planets Space. 63, pp. 1183-1192.

Durmaz, M., Karslioglu, M. O., 2014. Regional Vertical Total Electron Content (VTEC) modeling together with satellite and receiver Differential Code Biases (DCBs) using Semi-Parametric Multivariate Adaptive Regression B-splines (SP-BMARS). J. Geod., 89(4), pp. 347-360.

Fidani, C., 2010. The Earthquake Lights (EQL) of the 6 April 2009 Aquila Earthquake, in Central Italy, Nat. Hazards Earth Syst. Sci., 10, pp. 967-978.

Freund, F., 2005. Cracking the Code of Pre-Earthquake Signals, National Information Service for Earthquake Engineering, University of California, Berkeley.

Freund, F. T., Kulahci, I., G., Cyr, G., Ling, J., Winnick, M., Tregloan-Reed J., Freund, M. M., 2006. Air Ionization at Rock Surfaces and Pre-earthquake Signals, Journal of Atmospheric and Solar-Terrestrial Physics, 71, 17, pp. 1824-1834.

Freund, F., 2011. Pre-earthquake Signals: Underlying Physical Processes, Journal of Asian Earth Sciences, 41, pp. 383-400.

Frohlich, C., 2006. Deep Earthquakes, New York: Cambridge University Press, pp. 592.

Guo G, Wang, B., 2008. Cloud Anomaly before Iran Earthquake, International Journal of Remote Sensing, 29, pp. 1921-1928.

Hayakawa, M., Molchanov, O. A., 2002. Seismo Electromagnetics: Lithosphere-Atmosphere-Ionosphere Coupling. Terrapub, Tokyo, pp. 477.

Ikeya, M., 2004. Earthquakes and Animals: From Folk Legends to Science, River Edge, NJ: World Scientific, pp. 295.

Jin, R., Jin, S. G., Feng, G. P., 2012. M_DCB: Matlab code for estimating GNSS satellite and receiver differential code biases. GPS Solut. 16(4), pp. 541-548.

Jyh-Woei, L., 2011. Use of principal component analysis in the identification of the spatial pattern of an ionospheric total electron content anomalies after China's May 12, 2008, M=7.9 Wenchuan earthquake. Adv. Space Res. 47, pp. 1983-1989.

Klobuchar, J., 1986. Design and characteristics of the GPS ionospheric time-delay algorithm for single-frequency users. Procedings of the IEEE Position Location and Navigation Symposium. November 4-7, Las Vegas.

Klotz, S., Johnson, N. L., 1983. Encyclopedia of Statistical Sciences, John Wiley and Sons, New Jersey.

Komjathy, A., 1997. Global Ionospheric Total Electron Content Mapping Using the Global Positioning System, Dissertation. Dept. of Geodesy and Geomatics Engineering Technical Report 
No. 188. Univ. of New Brunswick, Fredericton, New Brunswick, Canada.

Kuo, C. L., Huba, J. D., Joyce, G., Lee, L. C., 2011. Ionosphere Plasma Bubbles and Density Variations Induced by Preearthquake Rock Currents and Associated Surface Charges, J. Geophys. Res., 116, A10317, doi:10.1029/2011ja016628.

Liperovsky, V. A., Pokhotelov, O. A., Liperovskaya, E. V., Parrot, M., Meister, C. V., Alimov, O. A., 2000. Modification of sporadic E-layers caused by seismic activity. Surv. Geophys. 21, pp. 449-486.

Liu, J. Y., Chen, Y. I., Chen, C. H., Liu, C. Y., Chen, C. Y., Nishihashi, M., Li, J. Z., Xia, Y. Q., Oyama, K. I., Hattori, K., Lin, C. H., 2009. Seismo-ionospheric GPS total electron content anomalies observed before the 12 May $2008 \mathrm{M}(\mathrm{w}) 7.9$ Wenchuan earthquake. J. Geophys. Res. doi:10.1029/2008JA013698.

Makalea, J. J., Kelley, M. C., Sojka, J. J., Pi, X., Manucci, A. J., 2001. GPS normalization and preliminary modeling results of total electron content during mid-latitude space weather event. Radio Sci., 36, pp. 356-361.

Mannucci, A. J., Wilson, B. D., Ewards, C. D., 1993. A new method for monitoring the Earth's ionosphere total electron content using the GPS global network. Proc. of ION GPS-93, Inst. of Navigation, pp. 1323-1332.

Namgaladze, A., Klimenko, M. V. V., Klimenko, V., Zakharenkova, I. E., 2009. Physical Mechanism and Mathematical Modeling of Earthquake Ionospheric Precursors Registered in Total Electron Content, Geomagnetism and Aeronomy, 49, 2, pp. 252-262.

Oyama, K. I., Kakinami, Y., Liu, J. Y., Kamogawa, M., Tetsuya, K., 2008. Reduction of electron temperature in low-latitude ionosphere at $600 \mathrm{~km}$ before and after large earthquakes. Journal of Geophysical Research, doi:10.1029/2008JA013367.

Parrot, M., Achache, J., Berthelier, J. J., Blanc, E., Deschamps, A., Lefeuvre, F., Menvielle, M., Plantet, J. L., Tarits, P., Villain, J. P., 1993. High-Frequency Seismo-Electromagnetic Effects. Physics Earth Planetary Int. ens. 77, pp. 65-83.

Priyadarshi, S., Kumar, S., Singh, A. K., 2011. Changes in total electron content associated with earthquakes $(M>5)$ observed from GPS station, Varanasi, India. Geomatics, Natural Hazards and Risk. 2(2), pp. 123-139.

Pulinets, S. A., 1998. Strong Earthquakes Prediction Possibility with the Help of Top Side Sounding from Satellites, Advances in Space Research, 21, 3, pp. 455-458.

Pulinets, S. A., Legen'ka, A. D., Gaivoronskaya, T. V., Depuev, V. K., 2003. Main phenomenological features of ionospheric precursors of strong earthquakes. J. Atmos. Solar Terrest. Phys. 65 , pp. $1337-1347$.

Pulinets, S. A., Boyarchuk, K., 2004. Ionospheric Precursors of Earthquakes. Springer, Berlin.

Pulinets, S. A., Ouzounov, D., Karelin, A. V., Boyarchuk, K. A., Pokhmelnykh, L. A., 2006. The Physical Nature of Thermal Anomalies Observed Before Strong Earthquakes, Physics and Chemistry of the Earth, Parts A/B/C, 31, 4-9, pp. 143-153.
Schaer, S., Gurtner, W., Feltens, J., 1998. IONEX: The IONosphere Map EXchange Format. Version 1, Proceedings of the 1998 IGS Analysis Center Workshop, Darmstadt, Germany.

Schaer, S., 1999. Mapping and predicting the Earth's ionosphere using the Global Positioning System. Dissertation, University of Berne, Switzerland

Schmidt, M., Bilitza, D., Shum, C. K., Zeilhofer, C., 2008. Regional 4-D modeling of the ionospheric electron density. Adv. Space Res. 42, pp. 782-790.

Silina, A. S., Liperovskaya, E. V., Liperovsky, V. A., Meister, C. V., 2001. Ionospheric phenomena before strong earthquakes. Nat. Hazards Earth Syst. Sci. 1, pp.113-118.

St-Laurent, F., Derr, J., Freund, F., 2006. Earthquake Lights and the Stress-Activation of Positive Hole Charge Carriers in Rocks, Physics and Chemistry of the Earth, 31, pp. 305-312.

Tronin, A., Hayakawa, M., Molchanov, O., 2002. Thermal IR Satellite Data Application for Earthquake Research in Japan and China, J. Geodynamics, 33, pp. 519-534.

Tronin, A., Biagi, P., Molchanov, O., Khatkevich, Y., Gordeev, E., 2004. Temperature Variations Related to Earthquakes from Simultaneous Observation at the Ground Stations and by Satellites in Kamchatka Area, Phys. Chem. Earth, 29, pp. 501506.

Ulukavak, M., 2016. Investigation of the Relationship between Equatorial and Mid-Latitude Earthquakes with Ionospheric TEC Anomalies, PhD. Thesis, Karadeniz Technical University, Turkey.

Ulukavak, M., Yalcinkaya, M., 2014. Examining The Effects of Huge Sunspots of 7 January 2014 over Local TEC Variation in Mid-Latitudes. EGU General Assembly Conference; 27 April 02 May, Vienna, Austria.

Ulukavak, M., Yalcinkaya, M., 2016. Investigation of the Effects of Solar and Geomagnetic Changes on the Total Electron Content: Mid-Latitude Region. EGU General Assembly Conference; 17 - 22 April 2016, Vienna, Austria.

URL-1:

http://www.iris.edu/hq/programs/education_and_outreach/anim ations/2 Fault Types. Accessing Date: 22 November 2014.

URL-2: https://www2.usgs.gov/faq/categories/9838/3312 Fault Types. Accessing Date: 22 November 2014.

URL-3:

ftp://ftp.ngdc.noaa.gov/hazards/cdroms/geohazards_v1/docume nt/647010.htm Fault Surfaces of Fault Types after Earthquake. Accessing Date: 22 November 2014.

Warnant, R., 1997. Reliability of the TEC computed using GPS measurements - The problem of hardware biases. Acta. Geod. Geoph. Hung. 32(3-4), pp. 451-459.

Zhou, Y., Wu, Y., Qiao, X., Zhang, X., 2009. Ionospheric anomalies detected by ground-based GPS before the Mw7.9 Wenchuan earthquake of May 12, 2008, China. J. Atmos. Solar Terrest. Phys., 71, pp. 959-966. 